\title{
Julio De Zan: dialéctica, militarismo y una nueva forma de heteronomía
}

\author{
Julio De Zan: dialectic, militarism and a new form \\ of heteronomy
} Julio De Zan: dialética, militarismo e uma nova forma de heteronomia

\author{
Alejandro Del Valle \\ Universidad Nacional de San Martín
}

Argentina

Recibido: 20/11/2020 - Aceptado: 13/5/2021

\begin{abstract}
Resumen
Desde el enfoque de la relación entre teoría y práctica, este trabajo trata de la unión que establece Julio De Zan entre el método dialéctico y una forma de praxis política que, desde el marco del pensamiento estratégico clásico, define como militarismo. Se intenta dar cuenta de la operación intelectual por medio de la cual se establecen equivalencias teórico-prácticas entre la dialéctica y el militarismo y cómo esta fundamenta una crítica al marxismo. Cómo conclusión, presentamos un argumento con el fin de problematizar la relación establecida por De Zan y rescatamos el contenido particular que el concepto de heteronomía adquiere desde la perspectiva de la filosofía de la liberación.
\end{abstract}

Palabras claves: filosofía de la liberación, marxismo, filosofía política, estudios latinoamericanos, teoría crítica.

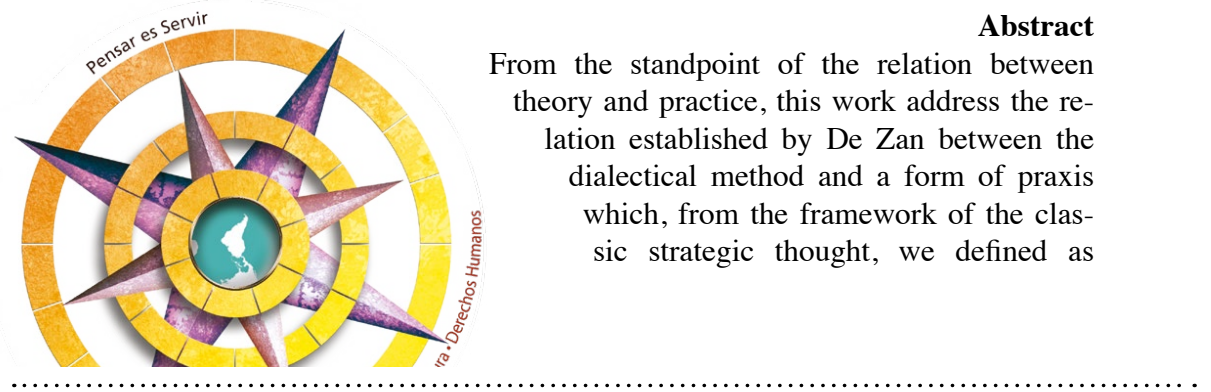


militarism. This work try to highlight the intellectual procedure through which theoretical-practical equivalences are established among the dialectical method and the militarism and how this intellectual procedure underpin a critic against the Marxism. As conclusion we present a critical argument in order to question the linkage established by De Zan and we value the particular content that the notion of heteronomy take from the perspective of the philosophy of liberation.

Key words: Philosophy of liberation, Marxism, political philosophy, Latinamerican Studies, Critical Theory.

\section{Introducción}

En el artículo La dialéctica en el centro y la periferia de 1972, Julio De Zan sostiene que mientras la aplicación del método dialéctico en el centro desencadena un proceso de liberación, su aplicación a nuestra totalidad iberoamericana produce el efecto contrario. Tal inversión de sentido que adquiere el método dialéctico, de herramienta de liberación en el centro a elemento ideológico encubridor en la periferia; resulta de su aplicación acrítica a un objeto distinto de aquel al cual fue aplicado por Hegel.

No entraremos aquí en el inmenso debate filosófico sobre cuál es el núcleo racional y la envoltura mística de la Lógica de Hegel, ni vamos a dar cuenta de los reiterados intentos en develar el sentido de la famosa inversión de Marx de la dialéctica especulativa a materialista o, como dice De Zan, de la discusión no resuelta entre la conexión y las diferencias entre la dialéctica de Hegel y la de Marx; solo señalamos esta cuestión para mencionar que De Zan trabaja sobre la hipótesis de la no diferencia entre la dialéctica hegeliana y la marxista.

Esta hipótesis le permite a De Zan discutir ciertas formas de la praxis revolucionaria que aparece como marxista en la instrumentación metodológica que manifiesta en nuestros países $(1974$, p.107) desde su interpretación de la dialéctica hegeliana. Dicho en otras palabras, a partir de lo planteado, nuestro autor ensaya una crítica a una praxis revolucionaria específica que nosotros definimos aquí como militarismo. A lo largo del trabajo fundamentaremos esta definición. Para comenzar, daremos cuenta de la posición de De Zan y de los fundamentos principales que la sustentan. 


\section{Teoría: dialéctica}

La trama principal del argumento es que la filosofía de Hegel recubrió con el ropaje de racionalidad filosófica muchos elementos de la vieja teología y del sentimiento religioso que así pasaron a formar parte de la conciencia moderna (De Zan, 1974, p.115). Uno de esos mitos de origen religioso es la "fe en el 'sentido' de la historia" que, bajo el ropaje de racionalidad filosófica, se expresa en el principio de inmanencia sin el cual el método dialéctico no podría funcionar. La aplicación del método dialéctico implica la actualización operativa de ese viejo mito de origen religioso.

El primer punto que establece el autor es que el método dialéctico no resiste la separación entre forma y contenido o, en términos hegelianos, entre método y sistema. Citamos el siguiente párrafo, en el cual De Zan especifica qué es la forma, qué es el contenido, y la compenetración inescindible entre ellos. Por su claridad y pedagogía no tiene desperdicio:

En Hegel la dialéctica se manifiesta antes que nada como la forma de la experiencia que la conciencia del individuo va haciendo a partir de la conciencia común y de la certeza sensible hasta elevarse a sí misma hacia la ciencia. Esta misma experiencia es la que se presenta en el proceso histórico de la autoelevación de los pueblos desde la esclavitud hacia la libertad. El curso de ambos procesos se halla igualmente determinado por la articulación inmanente del contenido, tanto de la vida de la conciencia del individuo como de la conciencia histórica o espíritu de un pueblo. La ley interna, que viene impuesta por la propia articulación del contenido en su despliegue como un todo orgánico, es la dialéctica; y la descripción de ese proceso en su racionalidad dialéctica tal como se manifiesta, es la fenomenología (De Zan,1974, p.108).

La dialéctica es entonces una ley interna, la manifestación formal de una experiencia que se haya determinada por un contenido que es inescindible de ella misma. El contenido es la vida de la conciencia del individuo, o bien, la conciencia histórica de un pueblo. La elevación de la conciencia del individuo hacia la ciencia es el mismo proceso que se da en los pueblos desde la esclavitud hacia la libertad.

Esta forma y este contenido son inescindibles, conforman un todo orgánicocuyo movimiento responde a una dirección que domina 
todo el proceso, un sentido ya establecido, una teleología: la dialéctica autoeleva al individuo hacia la ciencia y a los pueblos a la libertad. Además, el proceso se fundamenta a sí mismo desde adentro.

La dialéctica es ley interna y la articulación del contenido es inmanente. El movimiento dialéctico de la conciencia no puede fundarse, ni explicarse desde nada que sea exterior al proceso mismo: cada forma de conciencia y cada configuración histórica constituye un eslabón en la serie sucesiva y dialéctica de la historia del mundo contiene en sí misma la fuerza de su propia negación como el resorte que la impulsa más allá de sí misma.

De esta manera, la conciencia se autoeleva hacia un fin predeterminado movida por la fuerza de su propio contenido. La dinámica intrínseca de la dialéctica, la funcionalidad propia e inherente a ella misma, no puede darse sin el principio de inmanencia como su fundamento. La dialéctica, dice De Zan, "solamente puede funcionar sobre la base inmanente de la metafísica de la identidad" (1974, p.111). Ahora bien, a partir de esta exposición se comprende la funcionalidad específica de la negación determinada. Esto es sumamente importante, pues en la comprensión de la funcionalidad de esta categoría se basa la crítica de De Zan a la praxis militarista.

La negación determinada es la negación del saber constituido como tal en el momento que la conciencia se desdobla y hace la experiencia del resultado negativo (De Zan, 1974, p.109) que resulta de la contrastación entre su saber con respecto a la adecuación de ese saber con el ser en sí. La conciencia experimenta que aquello que ella consideraba el mundo no era más que $s u$ mundo.

La negación es determinada porque niega un saber determinado, el saber de acuerdo a la determinación que adquiere en el eslabón sintético presente. Además, la negación va a ser el motor de una constante autosuperación. Como dice De Zan, "la negación en cuanto negación determinada es ya en la experiencia que hace la conciencia lo que la mueve y engendra un contenido nuevo" (De Zan, 1974, p.110). Hay entonces una positividad en ella: la disolución de una determinación solidificada es la condición necesaria para que lo nuevo surja. Si hay síntesis, necesariamente hubo negación; y ella es la condición necesaria de una nueva síntesis.

Es ahora cuando debemos retomar los supuestos primeros: para que lo

4 Julio De Zan: dialéctica, militarismo y una nueva forma de heteronomía Alejandro Del Valle

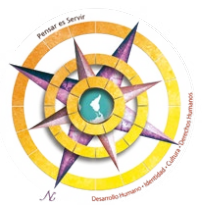


nuevo surja, la negación dialéctica no debe ser una mera forma, es decir, no puede estar separada del contenido. El contenido específico de la negación determinada es necesario, está determinado por la articulación inminente del contenido en su despliegue; es ese y no puede ser otro ya que es el adecuado a la solidificación que la negación niega.

La positividad de la negación descansa sobre el carácter determinado del contenido en el momento de la negación y dicha determinación surge de la articulación inminente del contenido. "Lo verdadero es el todo", dijo Hegel, "y el todo -agrega De Zan no es solamente el resultado sino éste juntamente con el proceso" (1974, p.110).

Por lo tanto, el todo es inmanente a cada uno de sus momentos y la negatividad hegeliana es inmanente al contenido determinado (De Zan, 1974, p.110). Cada estadio, cada etapa, cada solidificación de la serie eslabonada contiene en sí "toda la vida de la conciencia". Es decir que cada eslabón contiene la determinabilidad de toda la serie.

Al negarse la solidificación particular se vuelve a encontrar el todo que estaba "entrañado en ella misma" (De Zan, 1974, p.110). Se trata de la "universalidad inmanente a lo particular" (De Zan, 1974, p.110). La positividad de la negación determinada descansa, como se glosó, en su inseparabilidad del contenido, y a su vez, en el principio de inmanencia que habilita que al destruirse una "solidificación" no opere el vacío, sino el todo que estaba contenido, o "entrañado".

Cada eslabón tiene el doble carácter de ser determinabilidad del todo $\mathrm{y}$, al mismo tiempo, ser una cierta negación de la totalidad. La negación determinada niega la determinabilidad del todo y activa la totalidad negada haciéndola reencontrar consigo misma en la consolidación de una nueva síntesis. Este proceso solo puede ser comprendido atendiendo que nada es exterior a la articulación del contenido. La inmanencia significa que detrás de cada solidificación está la verdad, es decir el todo en su proceso inmanente, teleológico, que adquiere una nueva solidificación, una nueva determinación necesaria con cada negación determinada. Dice De Zan:

Entonces se comprende el resultado positivo de la negación que, al oponerse a una determinación solidificada, fija, y disolverla, permite reencontrar el todo que estaba entrañado en ella misma, la universalidad inmanente a lo particular, cuya determinación inmediata lo mantiene oculto (1974, p.110). 
Llegamos donde queríamos: la positividad de la negación determinada (o bien podríamos decir la dialéctica hegeliana como tal) descansa sobre la inseparabilidad de la forma y el contenido y sobre el principio de inmanencia.

\section{De la especulación a la praxis}

Para poder hacer la crítica de la praxis desde una argumentación teórica es necesario una operación, no siempre explícita y casi siempre solapada, que permita "ligar", por decirlo de algún modo, la reflexión especulativa con actos, los conceptos con acciones, las manifestaciones de la conciencia con operaciones políticas. El texto de De Zan tiene la virtud de explicitar tal operación, virtud que se debe a la rigurosidad evidente del filósofo y a la particularidad del tema tratado.

El derrotero de las arduas discusiones sobre el sentido de la famosa inversión de Marx de la dialéctica hegeliana pone en guardia a cualquier pensador serio de extrapolar mecánicamente, el método dialéctico de los márgenes originales descritos por Hegel. La trascendencia de esos márgenes originales implica para De Zan un cambio de objeto. Y tal procedimiento debe dar cuenta de su legitimidad. De acuerdo con esto, el autor se vio obligado a dedicar un cuarto de su artículo a fundamentar la tesis de la no diferencia entre la dialéctica hegeliana y la marxista (De Zan, 1974, p.106).

La no diferencia se fundamenta en la explicitación de aquellos presupuestos o principios lógicos necesarios que establecen desde adentro la dinámica inherente o la funcionalidad interna de la propia dialéctica. Sea cual fuese el objeto al cual se aplique el método dialéctico, independientemente de la legitimidad de tal operación pues, como ya dijimos, la forma y el contenido son inescindibles, los principios lógicos y los presupuestos del método son los mismos.

Esto implica que el método dialéctico lleva en sí una cierta funcionalidad que le es intrínseca y necesaria. En los propósitos propuestos (criticar un tipo de praxis), esta afirmación le sirve a De Zan para esquivar la ardua discusión teórica sobre el sentido de la inversión de Marx (en todo caso, dice él, es un problema del marxismo europeo) y fundamentar su crítica de la praxis en su crítica de la dialéctica hegeliana (1974, pp. 106-107) ${ }^{\mathbf{1}}$.

1 A su vez, De Zan insinúa tímidamente la débil hipótesis de que el materialismo dialéctico fuera, por fuerza de método, no más que idealismo.

6 Julio De Zan: dialéctica, militarismo y una nueva forma de heteronomía Alejandro Del Valle

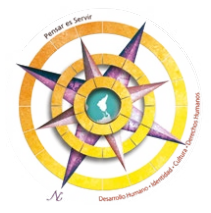


Sin embargo, allanado el camino entre Hegel y Marx, resta aún dar cuenta de la operación concreta que permite fundamentar la crítica de la praxis en la crítica de la dialéctica. Esta acción parece no necesitar ser ejercida por De Zan, por el contrario, se presenta como producto bruto de la contemplación: se basa en una interpretación de Marx.

La originalidad irrecusable de Marx dice De Zan invocando a Carlos Astrada, es la de "haber llevado la dialéctica al concreto terreno de la praxis histórico-social" (1974, p.113). La dialéctica materialista implica entonces un cambio de objeto; y principalmente, un cambio de carácter del método: de especulativo a práctico. De Zan resume en la siguiente formula esta modificación: "dialéctica de la praxis" (1974, p.113).

Las diferencias entre la dialéctica marxista respecto a la hegeliana no implican una modificación en la identidad del método, porque el dialéctico, lleva en sí su propia funcionalidad sostenida por principios que le son intrínsecos. Independientemente, del objeto y de la legitimidad de su aplicación. La tesis de De Zan indica que quién aplica la dialéctica queda "prisionero de los presupuestos sistemáticos de la filosofía de la inmanencia" que operaban en el "ámbito del idealismo alemán" (De Zan, 1974, p.106). Si el materialismo dialéctico implica un cambio de objeto y uno de carácter, no involucra una modificación de la técnica de su funcionalidad intrínseca, ni de los presupuestos que internamente lo fundamentan.

De Zan puede basar la crítica de la praxis en su crítica de la teoría por la trascendencia o la transposición de un instrumento metodológico de un plano a otro. Para esto es necesario previamente considerar a la teoría y a la práctica como planos o terrenos separados e independientes cuya vinculación radica, en este caso, en una transposición metodológica desde el primer plano al segundo.

Si teoría y práctica se combinan es por una operación intelectual que traspasa de un plano a otro la metodología que rige en el primero, y al hacerlo, se trasfiere, además, los presupuestos que rigen el análisis en el plano especulativo. Este es, en efecto, el movimiento teórico o la operación intelectual que legitima ligar la especulación y la crítica de la especulación a la acción política y a la crítica de la acción política.

Tal como lo expone De Zan, transpolar la crítica teórica a la de la praxis 
es posible gracias a la originalidad irrecusable de Marx de haber llevado la dialéctica del plano especulativo al de la praxis histórico-social. Pero más allá de la corrección o no de esta hermenéutica sobre la obra de Marx, la operación teórica que subyace a la crítica de la praxis realizada por De Zan es la que describimos.

\section{Práctica: militarismo}

\section{- A - Concepto}

Una de las innovaciones del pensamiento estratégico-militar moderno, cuyos fundamentos teóricos remiten a pensadores militares del siglo XVIII y principios del XIX, es, además de la conceptualización de la guerra propiamente dicha, la teorización alrededor del carácter, de los marcos generales y del contexto del conflicto armado. Se trata de pensar la naturaleza del todo, lo que significa considerar la parte simultáneamente con, o en el contexto de, el todo (Peltzer, 2014, p.61). Esta expresión corresponde a Carl Von Clausewitz, quizá el pensador militar más influyente y más reconocido de este período.

A grandes rasgos y a riesgo de simplificar bastante podemos señalar, de todos modos, con justicia, que las nuevas tendencias del clima intelectual alemán de principios del siglo XIX y la magnitud de los nuevos conflictos nacionales producto de las invasiones napoleónicas han sido las principales causas que dieron forma a lo que se denominó "Romanticismo militar" (Peltzer, 2014, pp. 26-28).

Estas conceptualizaciones se han desarrollado y han tenido influencia en la totalidad del pensamiento estratégico occidental, agregando definiciones y elementos en las diversas doctrinas operacionales alrededor del globo, incluyendo a la argentina. Una de las problemáticas fundamentales de estas nuevas teorizaciones militares era la relación entre guerra y política.

La famosa y ampliamente citada frase de Clausewitz de que "la guerra es la mera continuación de la política con otros medios"2 da la pauta de la nueva concepción alrededor de esta problemática. En esta formulación se indica que "lo único particular de la guerra con relación a la política es el carácter peculiar de los medios que utiliza" (Peltzer, 2014, 76).

Es importante señalar la preposición mit (mit anderen Mitteln) en la formulación clausewitziana y

2 Der Krieg ist eine bloße Fortsetzung der Politik mit anderen Mitteln.

8 Julio De Zan: dialéctica, militarismo y una nueva forma de heteronomía Alejandro Del Valle

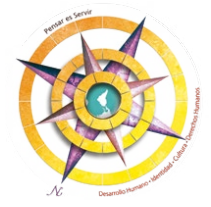


su correspondiente traducción por "con", puesto que las traducciones que optan por la preposición "por" (por otros medios) dejan abierta la interpretación a que la guerra signifique una suspensión de la política y/o un sustituto de la política.

Esta última interpretación implicaría que el elemento de la voluntad que opera en la definición general que Clausewitz hace de la guerra, a saber, que es "un acto de fuerza para imponer nuestra voluntad al adversario" (Peltzer, 2014, p.61), adquiere su contenido de la propia dinámica del conflicto armado y no de las condiciones políticas generales de las que este surge y dentro de las cuales se desarrolla. La preposición "con" señala sin duda que "la política siempre está funcionando", por lo tanto, la guerra es el medio particular del "continuo político" (Peltzer, 2014, p.76).

Esta concepción permite comprender adecuadamente, la distinción clausewitziana entre el objetivo o el fin político (Zweck), el ejercicio de la fuerza como medio y el propósito específico de la acción guerrera (Ziel) (Peltzer, 2014, p.61) ${ }^{\mathbf{3}}$. Desde esta distinción, la guerra siempre debe ser

3 En términos generales el objetivo político (Zweck) es imponerle nuestra voluntad al enemigo y el propósito específico de la acción guerrera (Ziel) desarmar al enemigo. comprendida como un acto político y su carácter es, por lo tanto, siempre instrumental (Peltzer, 2014, p.83).

Ahora bien, el fin político no solo legitima el ejercicio de la fuerza como medio, sino que lo decide en cuanto a su existencia y sus alcances: "la evaluación política introduce el cálculo racional de fines y medios, costos y beneficios" (Peltzer, 2014, p 77). El "elemento político", como dice Peltzer en un claro lenguaje castrense, determina los objetivos de la guerra (Ziel).

Por lo tanto, la guerra es el medio y el objetivo político el fin. Pero la guerra no es cualquier medio, además de su impronta característica de implicar el uso de la fuerza, es el medio adecuado y determinado para un fin político (Zweck) que siempre es específico. La política entonces no solo legitima el uso de la fuerza en función de las necesidades de alcanzar el fin político, sino que la determinación del "propósito específico" del uso de la fuerza (Ziel), la conformación de la fuerza en cuanto tal, su carácter, su organización, su método específico de aplicación, etc., está sujeto a la "racionalidad" que la política le impone.

La política hace de lo militar su elemento, imprimiéndole la forma que 
considera adecuada para los fines que persigue. Por lo tanto, si esto hace evidente que el fin político y el ejercicio de la fuerza "nunca pueden ser considerados separadamente puesto que en forma aislada son ininteligibles" (Peltzer, 2014, p.76), también es evidente que el uso de la fuerza en tanto medio requiere su subordinación a los "cálculos racionales" de la política.

Desde este punto de vista, si entendemos con Clausewitz y las principales líneas del pensamiento estratégico posterior, que es lo político aquello que define el conflicto armado en prácticamente todo lo que no sea estrictamente técnico en relación al uso de las armas y al abastecimiento de tropas, e incluso, como dijimos, la realidad del conflicto armado, el militarismo implica una subversión de esta jerarquización: lo militar se torna el elemento legitimante y estructurante de la actividad política.

Resultaría sumamente extenso y prácticamente inabarcable concebir todas las consecuencias teóricas y prácticas, de estrategia y de táctica que una concepción como esta implica. Solo mencionaremos aquí lo obvio: el objetivo militar (Ziel) subordina al político (Zweck). Por supuesto que esta subversión teórica de la jerarquización se expresa en la práctica con diferentes matices y nunca en forma pura, pero el predominio de lo militar sobre lo político es el rasgo dominante de este tipo de estrategia.

En este trabajo, no consideramos al militarismo como ideología o corriente de pensamiento, es decir, no vamos a considerar sus fundamentos filosóficos o teóricos, sino que llamamos aquí militarismo a esta subversión de las jerarquías de lo militar y lo político con respecto al pensamiento estratégico clásico. Militarismo es entonces, en este trabajo, un tipo específico de estrategia.

En la época en que Clausewitz escribía, el concepto de estrategia hacía referencia únicamente a lo que hoy se conoce por estrategia operacional. Es decir, en tiempo de Clausewitz, la estrategia le correspondía al general (el líder militar) y no al estadista (el líder político). No existía en aquel momento la definición extendida de estrategia de acuerdo con la dirección general en la guerra y en la paz correspondiente al más alto nivel de decisión en el Estado, tal como lo conocemos hoy (Peltzer, 2014, p.110).

En lo que sigue de este trabajo, cuando hablemos de estrategia nos referiremos a su concepto contemporáneo y no al moderno. Por lo tanto, la

10 Julio De Zan: dialéctica, militarismo y una nueva forma de heteronomía Alejandro Del Valle 
subversión de jerarquía que implica el militarismo va a ser tratado como un problema estratégico, en cual se incluye, consecuentemente, no solo lo referido a alcanzar el objetivo de la acción guerrera (Ziel), como en la época de Clausewitz, sino los problemas alusivos a la definición y, por ende, la concreción, del objetivo político (Zweck).

Haremos esto por dos motivos: primero porque discutir la relación entre la perspectiva teórica que desarrollamos anteriormente y el militarismo de acuerdo a la vieja definición de estrategia requeriría un esfuerzo de abstracción y adecuación de conceptos y de lenguaje que resulta artificial y absurdo; segundo, porque la crítica estratégica de De Zan a ciertas formas de la praxis revolucionaria presupone y se apoya en el concepto contemporáneo de estrategia.

- B - Equivalencias teórico-prácticas

Llegados a este punto hemos determinado tres aspectos importantes: por un lado, las especificaciones del método dialéctico y sus implicancias intrínsecas; por otro, hemos dado cuenta de la operación teórica por medio de la cual la teoría y su crítica se ligaa la práctica y a su crítica. Por último, definimos el concepto de militarismo desde la perspectiva del pensamiento estratégico clásico.

La transposición metodológica que permite ligar el plano especulativo con el plano práctico tiene su concreción en una serie de equivalencias o correspondencias entre ambos planos. El establecimiento de estas equivalencias es en concreto la forma de relación que adquieren los planos especulativos y prácticos en la crítica de De Zan "la positividad de la negación determinada se transforma en el principio político revolucionario de la positividad de la destrucción de las formas, de la lucha y la violencia en cuanto tal" (1974, p.113).

En el traspaso del plano especulativo al de la praxis histórico-social, la categoría de negación determinad $a^{4}$ realiza su conversión a principio político. Con base en esta operación, el término teórico o la categoría lógica de negación determinada, con la positividad que adquiere dicha negación tal como opera en el método dialéctico, adquiere un nuevo carácter, y como veremos una nueva funcionalidad, de acuerdo al contenido (objeto) sobre el cual se aplica el método dialéctico.

4 De aquí en adelante simplemente "negación". 
Al cambiar el objeto, la negación determinada cambia su carácter: si esta es categoría teórica o lógica en el plano especulativo, en el de la praxis histórico-social se transform" en principio político, es decir, en norma, en elemento doctrinario, en idea que guía la acción. En este nuevo plano, la positividad de la negación adquiere su equivalente en el despliegue de la violencia. Por lo tanto, la positividad de la negación teórica es la positividad de la violencia práctica.

Podemos decirlo de otro modo: al hacer reposar el método dialéctico desde afuera en otro objeto, la vacuidad de las formas toma su contenido del nuevo ente. La dialéctica pone sobre el terreno de la praxis histórico-social la sistematicidad de la totalidad que compone la propia aplicación del procedimiento y su movimiento teleológico interno; como si dijésemos que la forma de la nueva unidad y su lógica interna, lo pone la dialéctica en él.

Del plano de la praxis histórica social adquiere el método los elementos que serán considerados como su contenido y que son aquellos que se juegan en el propio plano de la praxis: los actores, los intereses, la lucha, las instituciones, la vida, la muerte y, por supuesto, la violencia.
Como vimos, a la funcionalidad intrínseca del método dialéctico subyace el supuesto teórico de una teleología inmanente a la totalidad del proceso, lo que De Zan llama el principio de inmanencia. Este supuesto que necesariamente acompaña al método es la forma pseudorracional que adquirió el residuo histórico de la vieja teología europea, el sentimiento religioso de la "fe en el "sentido" de la historia". Pero ¿cómo se fundamenta la tesis principal de De Zan de que el uso del método dialéctico avala o fundamenta la estrategia militarista? Para poder responder es necesario realizar la transformación principal que forma el cuadro completo de la tesis.

Siempre en el plano teórico, sobre el principio de inmanencia descansa la positividad de la negación, pues, como dijimos, la inmanencia refiere a una articulación intrínseca del contenido y la positividad de la negación describe a aquello que la negación hace nacer como consecuencia de la efectividad de su aplicación.

Dicho así, la positividad de la negación parece estar fundamentada únicamente en aquello que el contenido pone una vez que la negación está ya realizada. De modo que esta, en tanto es concebida como pura, solamente niega; su positividad

12 Julio De Zan: dialéctica, militarismo y una nueva forma de heteronomía Alejandro Del Valle

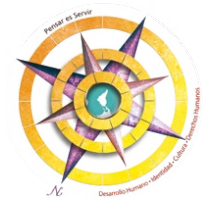


parecería no radicar en sí misma, sino en la síntesis que surge a sus espaldas. Sin embargo, esto no significa que la negación no contenga en sí su positividad; al contrario, es fecunda si solo ella misma es inmanente y lo negado es ya una cierta negación de la totalidad.

Esta es la condición para que la determinación solidificada, al ser negada, permita reencontrar la universalidad inmanente, la totalidad que estaba oculta en ella (De Zan, 1974, p.110); a su vez, también, lo es la negación determinada. Es fecunda porque es inescindible del contenido y a su vez es porque, como dice De Zan, "lleva en sí misma entrañada la superación que hace aparecer un mundo nuevo" (1974, p.116), esto es, la síntesis. Podemos concluir que el principio de inmanencia es el principio de la positividad de la negación.

Desde acá nos preguntamos ¿en qué se "convierte" este principio al traspasar los márgenes del plano especulativo e ingresar al plano práctico? En este caso la transformación no es lineal, no hay una correspondencia entre este principio y un despliegue inmediatamente fáctico en el otro plano como sucede en el caso de la negación. Por el contrario, el principio de inmanencia en el plano práctico toma la forma de una exención y una supresión. Dice De Zan:

Puede suponerse que, como en el proceso ideal estudiado por Hegel en la Fenomenología, tampoco es necesario poner en el proceso de la revolución una intencionalidad política que resultaría siempre una forma de heteronomía. Vuelve a jugar aquí, a la menara hegeliana, el principio de inmanencia y el postulado de una teleología inmanente a la cosa misma (arjé en autó), en este caso, inmanente a la cosa histórica, política, y que es lo que mueve desde dentro el proceso verdaderamente real (1974, p.113).

Esta cita es muy importante porque De Zan especifica qué es aquello que le aporta contenido al método dialéctico una vez realizado el traspaso al plano práctico. Dijimos: la dialéctica de la praxis es una transposición metodológica del plano especulativo al práctico; agregamos: entendiendo que el traspaso al plano práctico implica aplicar la dialéctica a la "cosa histórica", a la "cosa política" en tanto sustrato "político".

La incorporación de una intencionalidad política en la "cosa política", cuando esta última se concibe movida por una teleología inseparable e impersonal, no puede resolver en algo más que no sea una forma de 
heteronomía. De esta manera, el principio de inmanencia se convierte en la enajenación de un tipo de voluntad práctica, pues la equivalencia que este tiene en el plano práctico debe necesariamente, ser una supresión de algún elemento constituyente del nuevo plano. Si este principio implica una teleología inapelable del sustrato político entonces el riesgo de heteronomía es el de enajenar una intencionalidad que es precisamente política. En el plano práctico, este principio es la negación de la intencionalidad política.

Esto resuelve en la metodología de acción que De Zan critica. Pero, ¿qué significa en términos estratégicos?

\section{- C - Contenido estratégico}

Al traspasar la aplicación del método dialéctico del plano especulativo al práctico, se presuponen las categorías y la estructura formal del proceso sobre un contenido que se concibe como equivalente al esencial del ámbito especulativo. Sin embargo, al modificarse el objeto la forma se escinde del contenido y la negación, que en el plano teórico tiene la peculiaridad de hacer surgir aquello que espera necesariamente nacer por la articulación inmanente de su contenido esencial, adquiere en el plano práctico la pura negatividad destructiva sin coronar una síntesis superadora. Dice De Zan:

Solamente este contexto ideológico puede explicar cierta metodología de acción que se lanza a una guerrilla sin cuartel, pero sin otra estrategia visible que la invocación de una abstracta conciencia del pueblo, sin metas intencionalmente escalonadas hacia objetivos determinados conceptual y operativamente y prefijados en una escala temporal (1974, p.113).

El traspaso del plano teórico al práctico es aquí el contexto ideológico que explica una metodología de acción. La expresión contexto ideológico aviene, quizá haciendo uso de las connotaciones más evidentes del término ideología (dogmatismo, distorsión de la realidad, intereses de grupo, adoctrinamiento, "falsa conciencia", etc.) con una acción no solo ineficaz en términos militares o políticos, sino una que se presenta inmediatamente, como desprovista de racionalidad, que parece ejecutarse al margen del cálculo racional que la contiene y la justifica, que, en definitiva, solo puede explicarse ideológicamente.

El contexto ideológico se construye a partir de la trasposición metodológica que describimos. La escisión entre forma y contenido que esta

14 Julio De Zan: dialéctica, militarismo y una nueva forma de heteronomía Alejandro Del Valle

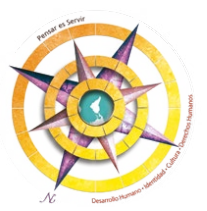


operación intelectual implica vacía las formas dialécticas de su contenido esencial. Sin el sustento ni el continuo subyacente que las determina y que oficia como su fundamento quedan operando "en el aire". De esta manera, la negación determinada, infecunda si se escinde del contenido, se transforma en la inefectividad de una acción militar sustentada en el vacío. Pero ¿cómo se da el vacío en el plano práctico? y ¿qué es ese vacío para la estrategia?

La violencia práctica se apoya en el equivalente del principio de inmanencia, es decir, en el vacío dejado por la supresión de la intencionalidad política. El sustrato político sin intencionalidad intrínseca toma la forma de un artefacto ideológico que fomenta la fe en el desenvolvimiento impersonal de un contenido ilusorio, etéreo y difuso, una abstracta conciencia del pueblo incapaz de entrañar a la acción violenta de la positividad de un objetivo político. Sin la efectiva articulación teleológica del contenido, la violencia es pura forma vacía, pura destrucción.

Desde el punto de vista estratégico, las falencias operacionales de la acción guerrillera hay que buscarlas en la racionalidad política en la que se encuadra y no en el propio dinamismo de su ejercicio. Las metas intencionalmente escalonadas hacia objetivos determinados conceptual y operativamente prefijados en una escala temporal no es algo que la acción guerrera pueda otorgarse a sí misma, sino que necesita de la lógica del cálculo político que le viene de afuera. ${ }^{5}$ Por lo tanto, si la fecundidad de la negación teórica remite al carácter inescindible de la forma y el contenido, la ineficacia de la violencia práctica remite a una metodología de acción descontextualizada del continuo subyacente que la determina.

Fijar la adecuación entre los fines políticos (Zweck) y los medios corresponde al más alto nivel estratégico (político). Si el medio es la acción armada, su eficacia estratégica remite a la adecuación del fin político (Zweck) con los propósitos específicos de la acción armada (Ziel) (Peltzer, 2014, p,69). Por lo tanto, la carencia de las metas escalonadas a las que se refiere De Zan es una falencia operacional, cuya causa está en un erróneo cálculo político.

Es demasiado superficial y pedante decir que las acciones guerrilleras en Argentina se fundamentaban en mistificaciones ideológicas, tampoco basta con repetir el deficiente lugar

5 Esta afirmación refiere a la diferencia entre guerra absoluta y real, o total y limitada según terminología actual. C. F. Peltzer, 2014, pp. 61-83. 
común de que las acciones guerrilleras argentinas de la década de los 70 respondían a una fe mesiánica en el determinismo histórico. Es evidente, de todas formas, que pueden rastrearse nítidos remanentes de estos discursos en la exposición de De Zan. Sin embargo, el objetivo de este trabajo es otro; de lo que aquí se trata es de ver qué significa, qué papel juega y cómo opera la "abstracta conciencia de pueblo" para la estrategia.

Lo inmediato es decir que el contexto ideológico que fundamenta el accionar guerrillero implica una caracterización errónea o equivocada de las condiciones políticas objetivas dentro de las cuales se desarrolla la intervención práctica. Esto es correcto, sin embargo, la tesis de De Zan es aún más radical.

Desde el punto de vista estratégico, la aplicación del método dialéctico pone en juego una tendencia que se orienta hacia la desvalorización y la depreciación del "continuo político", cuya persistencia por el medio específico del uso de la fuerza es la guerra. Los problemas del cálculo político-racional, la incertidumbre, la probabilidad y el azar, se entienden de algún modo solucionados o conjurados por el principio de inmanencia y la teleología.
Si se cree que con la destrucción de las formas surge por sí solo el mundo nuevo, como argumenta De Zan, entonces el continuo político se diluye y la crítica intencional de las condiciones objetivas (De Zan, 1974, p.116) comienza a ocupar un lugar subordinado a la estrategia operacional. Como si dijésemos que todo aquello que el elemento político aporta para la eficacia de la acción armada esté ya dado por la articulación inmanente e impersonal del sustrato.

La abstracta conciencia del pueblo encierra la negativa al análisis pormenorizado de los elementos que constituyen la realidad política concreta. La acción militar se libera de los contornos que le impone la política y se vuelve el elemento predominante y estructurante del conjunto de la actividad.

El conflicto armado queda como la única referencia para una directriz de acontecimientos y opciones posibles, por fuera del cálculo político que se supone racional. Descontextualizada, y siendo la parte preponderante de un todo que la excede y que se desvanece en cada afirmación de su predominio, la guerra aparece como la positividad del cambio histórico, y la política, su continuidad con otros medios. 


\section{Conclusión}

La argumentación de De Zan apunta a instalar la idea de una linealidad entre la utilización del método dialéctico y la estrategia militarista. El análisis se estructura principalmente a partir de establecer una serie de elementos equivalentes entre el plano de la teoría y el de la praxis. Los elementos que detallamos son los de la negación determinada y el principio de inmanencia. El primero tiene semejanza en el despliegue de la violencia; y el segundo en la tendencia a la supresión estratégica del cálculo político-racional.

Se puede apreciar que el principio de inmanencia invierte su funcionalidad en el traspaso de un plano a otro; en el teórico es condicionante imprescindible de la positividad de la negación; en la práctica opera a la inversa, distorsionando los elementos del cálculo político-racional, ejerciendo una fuerza contraria a la tendencia que aporta efectividad a la acción armada. Por esto, este principio que otorga positividad a la negación en el plano teórico opera en el práctico negándosela.

Queda claro que De Zan no plantea un desfasaje entre la dialéctica y el militarismo, sino que su argumento apunta a una concordancia entre esta teoría o este método y esta "forma de praxis". Claro que esta correlación puede ser matizada con ejemplos de fuerzas políticas que se reclaman y se han demandado marxistas, incluso en la época en la que escribió los textos tomados para este análisis, que han utilizado el método dialéctico como su principal herramienta teórica y no han adherido a la estrategia militarista, ni han formado parte de acciones guerrilleras.

Como es sabido, el marxismo y el rechazo al militarismo no necesariamente implica una postura pacifista. Es un tema que claramente, excede los marcos de esta monografía, pero el marxismo ha dado tanto en teoría, como en la práctica pruebas de diversas formas de administrar, conceptualizar y organizar la violencia que exceden la linealidad teórico-práctica establecida por De Zan. Por otra parte, sobran ejemplos de fuerzas políticas que han optado por el militarismo o que han organizado acciones guerrilleras sin considerar a la dialéctica un método válido, ni al marxismo una referencia teórica (Werner \& Aguirre, 2009, pp. 259-402).

Por otra parte, no es algo novedosos asignarle al marxismo una inevitable heteronomía, sin embargo, la originalidad del argumento De Zan, 
calibrado desde la perspectiva de la filosofía de la liberación, radica en el carácter particular que la heteronimia adquiere cuando se la conceptualiza a partir de la estructura de la dependencia. Tomado desde un punto de vista puramente teórico, la linealidad que De Zan establece entre el método dialéctico y el militarismo no sería un problema estricto del marxismo latinoamericano.

Argumenta que el principio de inmanencia o la fe en la historia, puede recaer en una forma de enajenación en la que los "hombres de acción transfieren su iniciativa política, su capacidad creadora, su responsabilidad y hasta su propia lucidez intelectual a la totalidad impersonal" (De Zan, 1974, p. 115).

Pero puesto que la explicación del movimiento por medio de una teleología inmanente a la "cosa misma" (arjé en autó) (o una articulación unida a una totalidad impersonal) es una conceptualización que tiene sus raíces en los postulados lógicos fundamentales del método, es razonable afirmar que la enajenación de la voluntad (y el predominio del uso de la fuerza en el cálculo estratégico que de ella puede surgir) es una problemática del esquema teórico-práctico de la dialéctica que excede los márgenes estrictos de la periferia.
No es entonces en la teoría dónde hay que buscar las causas del carácter específico de heteronomía en la que deriva la aplicación del método dialéctico en la periferia. Para comprender este carácter específico es necesario dar cuenta de las razones históricas que constituyen la estructura de la dependencia.

Vale la pena insistir en la perspectiva teórica de la filosofía de la liberación como el enfoque que, creemos, consolida el rasgo realmente original de la crítica de De Zan. Porque las interpretaciones que acusan al marxismo de derivar inexcusablemente en una heteronomía suelen leer en el marxismo el crudo determinismo económico; o bien, acentuando los orígenes metafísicos de los principios formales de la dialéctica (argumento que De Zan retoma), se afirma que la ausencia de autonomía de la voluntad está dada por la fe ciega en un principio abstracto, especulativo o de origen religioso.

Aquí sin embargo, el marxismo deriva en heteronomía no por aplicar la dialéctica al sustrato material o, si se quiere, económico, que constituye la "cosa histórica" tal los fundamentos del materialismo histórico (Marx \& Engels, 2014, pp. 16-31); ni tampoco por subordinar la voluntad a los designios de un principio extramundano;

18 Julio De Zan: dialéctica, militarismo y una nueva forma de heteronomía Alejandro Del Valle 
sino que la heteronomía que se produce en la periferia es la enajenación de la "intencionalidad política" como producto de una configuración particular del propio sustrato político.

Tengamos en cuenta que, por una parte, De Zan concibe, en evidente clave hegeliana, al "espíritu de un pueblo" como el "sujeto de la historia” (De Zan, 1974, p.112); por otra, tal como mencionamos con anterioridad este trabajo, la "cosa histórica" es "cosa política". Por lo tanto, a partir de estas coordenadas, es lógico entender que la estructura de la dominación es una situación política determinada y particular que refiere al espíritu de los pueblos.

En el artículo que tomamos como base para este trabajo, De Zan expone dos razones históricas que constituyen la situación de dependencia. La primera es que "nuestro propio ser no está dado todavía en sí ni puede ser supuesto como lo en sí desde el comienzo" (De Zan, 1974, p.117). Punto central dónde intenta resolver mediante la aplicación del método hermenéutico tal como está explicitado en su texto de 1975: Para una filosofía de la cultura y una filosofía política nacional.

La segunda es que "la estructura de la dependencia no es ya una duplicación de la conciencia como en la dialéctica hegeliana del amo y el esclavo [...] sino que implica la presencia de una alteridad irreductible" (De Zan, 1974, p.117). Estas razones históricas que expone De Zan están en sintonía con la argumentación que realiza en un artículo inédito, titulado Filosofía e historia. A propósito de la cuestión del sentido de la filosofía latinoamericana, en el cual se resalta la alienación cultural como un rasgo dominante de la estructura de la dependencia y se menciona que una de las consecuencias más nefasta de la situación general de la dependencia es un problema de autenticidad. En otras palabras, la estructura de la dominación es una determinación particular del sustrato político que contiene o implica una situación o una determinación particular de los sujetos históricos entre sí.

A estas dos razones agregamos una tercera que podría leerse como la contraparte de la primera que mencionamos en el párrafo anterior, cuyo contenido alude a las condiciones externas de la filosofía hegeliana, como suele denominarse a las condiciones sociales de producción de una obra, y que da cuenta de la situación histórica y política del dominador.

Dice De Zan: "Una filosofía como la de Hegel es expresión de la 
conciencia de sí que ha llegado a tener Europa en cuanto creadora y dueña de su propia historia, de un destino ya coronado de grandes realizaciones que se poseen como patrimonio propio" (1974, p.112). En un polo un pueblo autoconsciente, dueño de su propia historia, poseedor de un patrimonio de grandes realizaciones; en el otro, un pueblo cuyo ser "no está dado todavía en sí."

De esta concepción es de la cual surge el nuevo contenido que adquiere la categoría de heteronomía en la crítica de De Zan. En este caso, no se enajena la voluntad hacia las determinaciones de la materia, ni hacia un principio metafísico, sino hacia otra determinación del espíritu o bien, ya que en la estructura de la dominación los sujetos históricos, esto es, los espíritus de los pueblos no conforman una "totalidad cerrada", sino una "multiplicidad irreductible" (De Zan, 1974, p.115), se enajena la voluntad hacía la determinación histórica del espíritu de otro pueblo.

La situación de dominación que describe De Zan se configura entre el espíritu de un pueblo y de espíritu de otro pueblo, entre un sujeto histórico y otro sujeto histórico. El sujeto de la enajenación y el objeto de ella no implican una diferencia de planos existenciales. La estructura de la dominación equipara los polos en juego al concebirlos desde el mismo sustrato histórico-político. Ambos, dominado y dominante, ejecutan su acción en el mismo plano de la política y de la historia.

Es tema que merece otro trabajo, aunque vale la pena mencionar, la enorme discusión respecto a la búsqueda de autenticidad en las siempre más o menos veladas napas subterráneas de la cultura, que lleva a concebir la necesidad de hacer explícita, dentro de lo posible y mediante algún método preestablecido, una identidad étnica o un ethos que pondría en acto una totalidad catalizadora de la energía de las masas en un supuesto estado potencia ${ }^{6}$ (De Zan, 1974,p.112) y no buscar esa energía ya cristalizada en las manifestaciones de autoorganización concreta de lucha, más o menos institucionales, sea cual fuese la forma que tomen (comités de lucha, consejos de fábrica, coordinadoras interfabriles, asambleas populares, soviets, etc.) y más allá de previas develaciones o manifestaciones ideológicas que se crea a priori que dichas instituciones deban tener.

Independientemente de esto último, creemos que la gran virtud

6 Para un desarrollo en profundidad de este argumento ver: De Zan, 1975. 
conceptual y práctica de la crítica de De Zan es que el concepto de heteronomía ya no significa una enajenación a un principio superior, sea metafísico, científico, materialista o idealista; sino que la enajenación tiene la acritud profana de poner la propia voluntad "a disposición de quienes tienen concretamente el poder real" (De Zan, 1974, p.115).

\section{Referencias}

De Zan, J. (1975). Para una filosofía de la cultura y una filosofía política nacional, en AA.VV., Cultura Popular y Filosofía de la Liberación. Buenos Aires: Fernando García Cambeiros.

De Zan, J. (1974). La dialéctica en el centro y en la periferiaen AA.VV., Hacia una filosofía de la liberación latinoamericana. Buenos Aires:Bonum.

De Zan, J (S.F). Filosofía e historia. A propósito de la cuestión del sentido de la Filosofía Latinoamericana. Inédito.
Marx, K., Engels, F. (2014). La ideología alemana. Madrid: Akal. .

Peltzer, J (2014). Jomini \& Clausewitz en la Doctrina Operacional Argentina. Buenos Aires: EUDE.

Werner, R. \& Aguirre, F. (2009). Insurgencia obrera en la Argentina 1969-1976. Buenos Aires: Ediciones IPS. 